\title{
Impact of Tailored Educational Program of Quality of Life Improvement on Women Undergoing Breast Cancer Treatment at El-Minia Region, Egypt
}

\author{
Fatma S. Nady ${ }^{1}$, Mamdouh E. said ${ }^{2}$, Entisar M. Youness ${ }^{3}$, Hanan E. Hassan*4 \\ ${ }^{1}$ Assistant lecturer in Maternal \& Newborn Health Nursing, Faculty of Nursing, Beni-Suief University \\ ${ }^{2}$ Professor of oncology, Faculty of Medicine, Beni-Suief University \\ ${ }^{3}$ Assistant Professor of Obstetrics and Gynecological Nursing, Faculty of Nursing, Assuit University \\ ${ }^{* 4}$ Maternal and Newborn Health Nursing, Faculty of Nursing, Beni-Suef University, Egypt \\ *nona_nano_1712@yahoo.com
}

\begin{abstract}
Background: There are 7.2 million female cancer survivors today, it is estimated that 40,450 women will die from breast cancer subsequently, unprecedented survivorship issues concerning psychosocial needs for women have become the new focus for healthcare providers and researchers.

Aim: Assess the effectiveness of education program on quality of life (QOL) improvement in women undergoing treatment for breast cancer.
\end{abstract}

Study design: A quasi experimental.

Sample \& settings: A purposeful sample of 64 women diagnosed with breast cancer that attended the oncology institute, El-Minia region, and recruited randomly.

Tool: Semi-structured interview questionnaire included reproductive concern scale female sexual function index, impact of event scale, and functional assessment of cancer therapy-breast.

Results of this study indicated improvement in cancer QOL after administration of the program as (65.62\%) of the study group as compared with (6.25\%) of the control group had good QOL and (0.0\%) of the study group vs. $(25.0 \%)$ of the control group had poor quality of life.

Conclusion: The health education program showed evidence of improved QOL, with a reduction in the sexual dysfunction, and lower stress levels. Thus, it can be said that health education program enhances physical, social, emotional, functional wellbeing and additional concerns related to breast cancer, and on enabling women to proactively live with a cancer condition.

Recommendations: Based upon findings of the current study, it is suggested to heighten awareness \& knowledge about the treatment-related side effects among the nursing staff in the department for the nursingcare of this group of patients.

Keywords: Breast cancer- reproductive concerns- quality of life.

\section{INTRODUCTION}

Breast cancer is the most common cancer among American women. An estimated 252,710 women in the United States will be diagnosed with invasive breast cancer, and 63,410 women will be diagnosed with in situ breast cancer. An estimated 2,470 men in the United States will be diagnosed with breast cancer. It is estimated that 41,070 people $\left(40,610\right.$ women $\& 460$ men) will die from breast cancer. ${ }^{[1]}$ 
Impact of Tailored Educational Program of Quality of Life Improvement on Women Undergoing Breast Cancer Treatment at El-Minia Region, Egypt

Breast cancer is considered the leading cause of cancer death among females in economically developing countries. ${ }^{[2]}$ Prevalence of breast carcinoma is high in Egypt and the cases of breast cancer constitute 29\% of cancer cases treated at the national cancer institute and the most frequent malignant tumor in women worldwide. In Egypt, it is the most common cancer among women, representing 18.9\% of total cancer cases among the Egypt National Cancer Institute's (NCI) series of 10,556 patients during the year 2001. ${ }^{[3]}$ Moreover, Ibrahim et al. reported that 19105 female cases diagnosed with Breast cancer in 2014 In Egypt. ${ }^{[4]}$

As the overall death rate for women with cancer declines, the number of survivors continues to grow. Recently, the NCI Office of Cancer Survivorship (2010) reported that there are 7.2 million female cancer survivors today, which include $68 \%$ surviving at least an average of 5 years after diagnosis. Subsequently, unprecedented survivorship issues concerning psychosocial needs for women have become the new focus for healthcare providers and researchers. ${ }^{[5]}$

In spite of increasing survival rate of patients with breast cancer, many women with this disease suffer from long-term physical \& psychological problems resulting from the existing combined treatments for some of the cancer treatments can often cause numerous lasting adverse effects and have a significant effect on QOL of breast cancer survivors. ${ }^{[6,7]}$ On the other hand, completing treatment courses, patients with cancer are confronted with a series of challenges, which are different from the challenges faced in days and weeks after diagnosis. In other words, upon diagnosing the disease, patients feel stress and distress and are frightened thinking of early death, disease prognosis and imposed roles and responsibilities. After a while, these challenges are replaced by chronic depression, financial problems regarding disease treatment, psychological \& physical complications of chemotherapy/radiotherapy, and even surgery. In addition, focus of the patient with the cancer in survival time changes from fear of death, distress regarding full treatment and recovery or adjustment with activities related to the treatment into the issues related to long-term survival. ${ }^{[8]}$ These people face issues like problems in sexual relations \& change in mental image, fatigue, comorbidities resulting from cancer treatments, including incidence of secondary cancers, risk of psychological distresses, depression periods and disturbances in life style. In fact, these people may experience painful symptoms and complaints even several years after diagnosis. ${ }^{[9,6]}$ Therefore, there is a need for attempts toward enhancing physical performance and QOL of this category of patients. ${ }^{[7]}$

QOL is a multidimensional construct that encompasses physical, social, emotional, and functional well-being.

${ }^{[10]}$ In the context of cancer, an individual's baseline functioning in these areas is impacted by the disease and its associated treatment. ${ }^{[11]}$ Health related QOL is a state of well-being with two components: (1) the ability to perform the tasks of daily living that reflect physical, psychological \& social well-being, and (2) the individual's satisfaction with levels of functioning \& control of the disease and/or the associated treatment related sequelae. ${ }^{[12]}$

Studies show that patients with breast cancer depend on treatment caring providers for receiving the information required on their disease \& controlling their situation. ${ }^{[13]}$ Nurses, as one of the members of treatment team, have an important role in diagnosis, treatment, and caring patients with cancer and as they spend more time with the patient compared to the other treatment team members, they may be the first people who can recognize the needs of patients as well as their families and be effective in controlling disease complications and treatment and enhancing QOL of the patients. ${ }^{[6]}$

\section{Significance of the Study}

Breast cancer is the most commonly occurring form of cancer in women. In 2014, approximately 18,660 new cases were diagnosed in Egypt. The breast mortality rate was 21.6\%. ${ }^{[14]}$ About $25 \%$ of breast and gynecologic cancers are diagnosed in women under the age of 50. ${ }^{[15]} \mathrm{An}$ increase in the number and distress of symptoms is associated with decreased QOL. ${ }^{[16]}$ Women have indicated that unmanaged symptoms have a negative impact on all the dimensions of QOL including their physical, social, psychological, and spiritual well-being. ${ }^{[17]}$ 
Impact of Tailored Educational Program of Quality of Life Improvement on Women Undergoing Breast Cancer Treatment at El-Minia Region, Egypt

The usual care given during cancer treatment tends to focus on procedures, side effects of treatment, and its process rather than on the resulting symptoms and their management. Therefore, a more comprehensive approach to helping women with their symptom management is required.

\section{AIM OF THE STUDY}

Assess the effectiveness of education program on QOL improvement in women undergoing treatment for breast cancer.

\section{RESEARCH HYPOTHESIS}

The QOL of the women undergoing treatment for breast cancer will be improved after implication of the educational program.

\section{SubJECTS AND MeTHOdS}

\section{Research Design}

A quasi experimental (Non Equivalent pre-test, post-test control group) research design was adopted.

\section{Settings}

The study was conducted in the oncology institute which was the only health-care setting providing health-care services to breast oncology women in El-Minia region.

\section{SAMPLE}

A purposeful sample of 64 women diagnosed with breast cancer that attended the oncology institute and recruited randomly. The sample divided into 2 main groups 32 each study group who followed the recommended QOL improvement educational program and control group who followed the routine care.

\section{Tools}

Data were collected by objective self-administered questionnaire at baseline, follow up, and evaluation assessment. Assessment was conducted prior to the initial chemotherapy cycles, follow-up was conducted during subsequent chemotherapy cycle, while evaluation (post intervention) assessment was conducted three weeks after the last chemotherapy dose was received.

\section{The First Part Was To Obtain}

\section{A-Socio-Demographic Data}

As age, marital status, menstrual status, education, employment, residence, social support, and family income.

\section{B-Menstrual History}

As age at menarche. Menstrual status: "premenopausal, post-menopausal, peri-menopausal",

\section{C-Clinical Characteristics}

include Information about disease site (breast), previous consultation for gynecological complaints, family history of breast cancer, months since diagnosis, stage at diagnosis, and type of treatment which may include surgery, radiation, chemotherapy, and/or hormonal therapy.

\section{The Second Part Involved}

A- The Reproductive Concerns scale (RCS). ${ }^{[18]}$ It was developed for female cancer patients. It examines concerns among survivors whose reproductive ability may have been impaired or removed due to disease and/ 
Impact of Tailored Educational Program of Quality of Life Improvement on Women Undergoing Breast Cancer Treatment at El-Minia Region, Egypt

or treatment. It consists of 14 items assessing the extent to which women viewed reproductive concerns as a problem: Items are rated on a five-points Likert scale ranging from 0 (not at all) to 4 (very much). Items are summed for a total score (with two positively-worded items"5, 10, 15" reverse-scored). Scores ranged from 0 to 56 with a higher score indicating greater reproductive concerns and relatively poor QOL, poor satisfaction with life, and depression. .

B- Female Sexual Function index (FSFI) ${ }^{[19]}$ It is a 19-item self-report measure to assess sexual functioning during the past four weeks. Items are rated using a six-point Likert scales (e.g.; Over the past four weeks, how often did you feel sexual desire or interest? $5=$ almost always or always, $4=$ most times (more than half the time). Principal components analysis yields six subscales: desire, arousal, lubrication, orgasm, satisfaction, and pain. Items are rated using a six-point Likert scales (e.g.; Over the past 4 weeks, how often did you feel sexual desire or interest? $5=$ almost always or always, $4=$ most times (more than half the time). The total FSFI score under 26.55 was accepted as female sexual dysfunction (FSD).

\section{Part three Involved}

A- Cancer-specific stress. ${ }^{[20]}$ The Impact of Events Scale Revised (IES-R) is a 22-item self-report questionnaire translated into Arabic by the researcher to assess traumatic stress reactions to cancer diagnosis \& treatment. Factor analytic studies indicate that the measure assesses three factors (corresponding to the post-traumatic stress disorder "PTSD" clusters): intrusive thoughts (i.e.; "I had dreams about being a cancer patient"), avoidant thoughts/behaviors (e.g., "I tried not to talk about it (cancer)"), and hyper arousal (e.g.; "I was jumpy \& easily startled"). Women rated the frequency of these feelings or events during the previous week, using a five-point Likert scale ranging from $0=$ not at all to $4=$ extremely. Items were summed for a total score that ranges from 0 to 88 , with higher scores reflecting greater cancer-related stress. Authors recommend a cut-off score of 33 for identifying patients with clinical symptoms of post-traumatic stress. ${ }^{[21]}$

\section{Scoring System}

On this test, scores that exceed 24 can be quite meaningful. High scores have the following associations:

1- 24 or milder: PTSD": PTSD is a clinical concern. Those with scores that is high who do not have full PTSD will have partial PTSD or at least some of the symptoms. ${ }^{[22]}$

2- 33 and above moderate "PTSD": This represents the best cutoff for a probable diagnosis of PTSD. ${ }^{[23]}$

3- 37 or more "sever PTSD": This is high enough to suppress women immune system's functioning (even 10 years after an impact event). ${ }^{24]}$

$\boldsymbol{b}$ - Quality of life, The Functional Assessment of Cancer Therapy-Breast (FACT-B +4 ) Version 4 is a breast cancer-specific Health Related Quality of Life (HRQOL) instrument of the FACT system. The 41-item English and (simplified) Chinese FACT-B version 4 are divided into five subscales, namely Physical Well-Being (PWB), Social/family Well-Being (SWB), Emotional Well-Being (EWB), functional well-beings (FWB), and the additional concerns for breast cancer (BCS). ${ }^{[25,26]}$ We have reported the validity \& reliability of, and the comparability between the two language versions in an earlier study. ${ }^{[27]}$ Each item is rated on a 5-point Likert scale. Negatively worded items were recoded such that a higher score indicates a better HRQOL. The FACT-B total score is the sum of scores of all five subscales.

\section{Quality of Life Improvement Education Program}

The component of information provision provides thorough, accurate \& useful information on a women illness, treatment and self-care QOL. Content analysis of QOL identified three categories of attribute in cancer patients, physical, psychological \& interpersonal well-being. ${ }^{[28]}$ In general, QOL is a matter of women views of life, 
Impact of Tailored Educational Program of Quality of Life Improvement on Women Undergoing Breast Cancer Treatment at El-Minia Region, Egypt

and their satisfaction and happiness with it. ${ }^{[29]}$ Women in the nursing intervention group received tailored specialized care. The primary objective of the intervention was to assist women in developing \& maintaining selfmanagement skills and to facilitate their active participation in decisions affecting their subsequent treatment. Nursing interventions included symptoms assessment, management monitoring, and emotional support, and women education, coordination of resources, referrals, and direct nursing care through individualized symptom management education program.

\section{Content Validity}

The researcher distributed the questionnaire to a panel of five specialists in obstetrics \& gynecology nursing, oncology nursing staff, and medical related specialists in Beni-Suef and Assiut University to check the validity of the tool used.

\section{Pilot Study}

A pilot study was implemented on $10 \%$ of women included in the study to ascertain the relevance of the tools, and estimate the length of the time needed to fill the sheet. Analysis of the pilot study revealed that minor modifications are required. These modifications were done and women included in the pilot study were included in the total sample.

\section{Procedure}

Once the permission was granted to proceed with the proposed study, oral consent was obtained from each woman. The researcher initiated data collection. Researcher reviews the visits appointment in the selected setting of the study. The researcher interviewed the women face to face in the day of visit in the Oncology Institute at El-Minia government in the outpatient clinic, waiting room 2 days per week from 9 a.m. to 2 p.m. Collection of data was from the control group who received routine care and the study group who received assessment and nursing intervention. The flow of intervention was through 5 sessions (may be less) for women received small number of doses with the average of one session every three weeks for four phases of nursing intervention program (pre and post). Data was collected through interviewing, assessment, implementation, and follow up \& evaluation phases.

\section{Ethical Considerations}

A written or oral consent accordingly to conduct the study was taken from each studied women to protect their rights before the start of the study. They were informed that they could withdraw at any time. A unique identifying number (subject ID) was assigned to the data collected from each woman to maintain confidentiality.

\section{Statistical Analysis}

All the statistical analysis was performed using SPSS package version 20. Collected data were coded and analyzed. Descriptive statistics for the variables were calculated.

\section{Inferential Statistics}

The data were tested for normality using the Anderson-Darling test and for homogeneity variances prior to further statistical analysis. Categorical variables were described by number \& percent (N \& \%), where continuous variables described by mean $\&$ standard deviation (Mean $\pm \mathrm{SD}$ ). Chi-square $\left(x^{2}\right)$ test used to compare between categorical variables where compare between continuous variables by paired $\&$ unpaired t-test. Pearson correlation coefficient ( $\mathrm{r}$ ) used to assess the association between continuous scales. A two-tailed $\mathrm{P}<0.05$ was considered statistically significant. All analyses were performed with the IBM SPSS 20 software. 
Impact of Tailored Educational Program of Quality of Life Improvement on Women Undergoing Breast Cancer Treatment at El-Minia Region, Egypt

\section{RESULTS}

Table (1) shows that no statistical significant difference between the two groups which denote homogeneity of the groups. The age range of the sample was 21 to 55 years. The mean age of the subjects in the study group was $39.5 \pm 6.2$ as compared with $41.2 \pm 7.3$ in the control group. Near to half of subjects $(46.9 \% \& 43.8 \%)$, respectively, in both groups were illiterate, majority of the subjects ( $84.4 \% \& 90.6 \%)$, respectively, in both groups were housewives. More than half (56.3\%) of the subject in study and (65.6\%) in the control groups live in rural areas. More than half of the subject of the study group (56.3\%) reported enough income and (65.6\%) of the control group reported in sufficient income. The mean of age at first child birth, and age at last child birth, in the study and control group was approximately similar $(21.6 \pm 3.5,19.6 \pm 5.1) \&(30.8 \pm 5.2,30.3 \pm 5)$, respectively. Number of living children in the study and control group was $(3.4 \pm 1.3,4.1 \pm 1.5)$, respectively. Near to half in the study and control group (56.3\%) were in premenopausal status.

Table (2) demonstrates that no statistical significant difference regarding to stage of cancer, as more than half of the study group (56.3\%) vs. (65.6\%) of the control group didn't know their stage of disease. Majority of the cases in the study group (93.8\%) Vs. (100\%) of the control group received chemotherapy.

Regarding to reproductive concerns, this was measured at one-time point only. Table (3) illustrates that majority ( $81.3 \%$ \& $78.1 \%)$, respectively, of the case in the study and control group were somewhat concerned, and the means of reproductive concerns of the study group were $(51 \pm 14.2)$ vs. $(45.9 \pm 12.6)$ of the control group with no statistical significant difference.

During the first visit, table (4) demonstrates that there was no statistical significant difference between the two groups of women, as the percentage of women with sexual dysfunction in the study and control group was (93.75\% \& 93.75\%), respectively, and the percentage of women who were healthy (have no sexual dysfunction) was similar in the two groups $(6.25 \% \& \mathrm{P}=1)$. During the last visit, there was a statistical significant difference in relation to impact of the health education program on sexual function, as there was a significant change in the sexual function index. The percentage of women with sexual dysfunction in the study and control group was $(71.8 \% \% \& 93.75 \%)$, respectively, and the percentage of women who were healthy (have no sexual dysfunction was $(28.12 \% \& 6.25 \%)$, respectively, in the two groups $(\mathrm{P}=0.043)$.

Table (5):- reveals that the majority (84.4\%) of the cases of the study and control groups had severe traumatic stress disorder, and (6.3\%) of the women in the study group Vs. (9.4\%) of the control group were healthy with no stress with no statistically significant difference $(\mathrm{P}>0.05$ (. In the last visit there was clear effect of the health education program on traumatic stress reactions to cancer diagnosis and treatment. As (18.8\%) of the study group, as compared with (68.8\%) of the control group had severe traumatic stress disorder, and (40.6\%) of the women in the study group Vs. (12.5\%) of the control group were healthy with no stress. ( $\mathrm{P} \leq 0.001)$.

In relation cancer specific QOL in the first visit, Table (6) reveals near to two-thirds (71.8\%) of the study group and control group had moderate QOL ( $\mathrm{P}>0.05)$. In the last visit there was clear effect of the health education program on cancer specific quality of life. As $(65.62 \%)$ of the study group as compared with $(6.25 \%)$ of the control group had good QOL and $(0.0 \%)$ of the study group vs. $(25 \%)$ of the control group had poor QOL. with statistically significant difference $(\mathrm{P}<0.001)$.

Table (7): demonstrates that there was no significant correlation between socio-demographic data and QOL as regards study and control groups in the first visit except on the study group, there was significant positive correlation with menopausal status and QOL, in the control group; there was a significant positive correlation between education of husband, income and QOL and significant negative correlation with presence of emotional illness and quality of life. Regarding the clinical characteristics, in the control group there was a significant 
Impact of Tailored Educational Program of Quality of Life Improvement on Women Undergoing Breast Cancer Treatment at El-Minia Region, Egypt

negative correlation between stage at diagnosis and QOL. In the last visit there is no significant correlation between socio-demographic data and QOL as regards study and control groups except on the study group, there was significant negative correlation with age at marriage and QOL and significant positive correlation with receiving surgical and chemotherapy and QOL.

Table (8): Illustrates that there is no significant difference between reproductive concerns and QOL in the study and control group in the first and last visit $(\mathrm{P}>0.05)$. Also in the first visit there was statistically significant difference between female sexual function and QOL in the study group as (100.0\%) of cases who had poor QOL had sexual dysfunction $(\mathrm{P}>0.05)$. There was statistically significant difference between cancer specific stress and QOL as $(100.0 \%)$ of the study group who had QOL had severe stress in the first visit (P>0.05), while in the last visit (66.7\%) of women who had good QOL had mild stress ( $\mathrm{P}>0.05)$.

Table1. Distribution of the Studied Women According to Their Socio-demographic Characteristics.

\begin{tabular}{|c|c|c|c|c|c|}
\hline \multirow{2}{*}{$\begin{array}{l}\text { Socio-demographic } \\
\text { Characteristics }\end{array}$} & \multicolumn{2}{|c|}{ Study } & \multicolumn{2}{|c|}{ Control } & \multirow{2}{*}{ P. value } \\
\hline & No. & $\%$ & No. & $\%$ & \\
\hline Age & \multicolumn{2}{|c|}{$39.5 \pm 6.2$} & \multicolumn{2}{|c|}{$41.2 \pm 7.3$} & 0.304 \\
\hline \multicolumn{6}{|l|}{ Education } \\
\hline Illiterate & 15 & 46.9 & 14 & 43.8 & \multirow{4}{*}{0.509} \\
\hline Read and write & 6 & 18.8 & 6 & 18.8 & \\
\hline Technical education & 6 & 18.8 & 10 & 31.3 & \\
\hline Higher education & 5 & 15.6 & 2 & 6.3 & \\
\hline \multicolumn{6}{|l|}{ Occupation } \\
\hline Working & 5 & 15.6 & 3 & 9.4 & \multirow{2}{*}{0.450} \\
\hline House wife & 27 & 84.4 & 29 & 90.6 & \\
\hline \multicolumn{6}{|l|}{ Residence } \\
\hline Urban & 14 & 43.8 & 11 & 34.4 & \multirow{2}{*}{0.442} \\
\hline Rural & 18 & 56.3 & 21 & 65.6 & \\
\hline \multicolumn{6}{|l|}{ Income } \\
\hline Enough & 18 & 56.3 & 11 & 34.4 & \multirow{2}{*}{0.079} \\
\hline Not enough & 14 & 43.7 & 21 & 65.6 & \\
\hline Age at first child birth & \multicolumn{2}{|c|}{$21.6 \pm 3.5$} & \multicolumn{2}{|c|}{$19.6 \pm 5.1$} & 0.075 \\
\hline Age at last child birth & \multicolumn{2}{|c|}{$30.8 \pm 5.2$} & \multicolumn{2}{|c|}{$30.3 \pm 5$} & 0.705 \\
\hline No. Of living children & \multicolumn{2}{|c|}{$3.4 \pm 1.3$} & \multicolumn{2}{|c|}{$4.1 \pm 1.5$} & 0.068 \\
\hline \multicolumn{6}{|l|}{ Menstrual status } \\
\hline Premenopausal & 18 & 56.3 & 18 & 56.3 & \multirow{3}{*}{0.733} \\
\hline Postmenopausal & 8 & 25 & 10 & 31.3 & \\
\hline Per menopausal & 6 & 18.8 & 4 & 12.5 & \\
\hline
\end{tabular}

Chi square test for qualitative data between the two groups

- Significant level at $P$ value $<0.05$ 
Impact of Tailored Educational Program of Quality of Life Improvement on Women Undergoing Breast Cancer Treatment at El-Minia Region, Egypt

Table2. Distribution of the studied women according to their clinical characteristics

\begin{tabular}{|l|c|c|c|c|c|}
\hline \multirow{2}{*}{ clinical characteristics } & \multicolumn{2}{|c|}{ Study } & \multicolumn{2}{c|}{ Control } & \multirow{2}{*}{ P value } \\
\cline { 2 - 5 } & No. & $\%$ & No. & $\%$ & \\
\hline Stage at diagnosis & & & & & \\
\hline Zero stage & 0 & 0.0 & 1 & 3.1 & \\
\hline First & 3 & 9.4 & 3 & 9.4 & \multirow{2}{*}{0.520} \\
\hline Second & 10 & 31.3 & 5 & 15.6 & \multirow{2}{*}{6.3} \\
\hline Third & 1 & 3.1 & 2 & 65.6 & \\
\hline Unknown & 18 & 56.3 & 21 & & \multirow{2}{*}{0.055} \\
\hline Treatment received \# & 23 & 71.9 & 29 & 90.6 & \multirow{2}{*}{0.151} \\
\hline Surgical removal & 30 & 93.8 & 32 & 100 & \multirow{2}{*}{0.794} \\
\hline Chemotherapy & 12 & 37.5 & 11 & 34.4 & \multirow{2}{*}{0.302} \\
\hline Radiotherapy & 3 & 9.4 & 1 & 3.1 & \\
\hline Hormonal therapy & & & & & \\
\hline
\end{tabular}

- $\quad$ Chi square test for qualitative data between the two groups

- $\quad$ Significant level at P value $<0.05$

- $\quad$ \#More than one option was checked

Table3. Distribution of the studied women according to their reproductive concerns

\begin{tabular}{|c|c|c|c|}
\hline Reproductive Concerns scale & Study & Control & $P$ value \\
\hline \multicolumn{4}{|l|}{ RCS total } \\
\hline Range & $(30-78.9)$ & $(25.6-77.8)$ & \multirow{3}{*}{0.168} \\
\hline Mean \pm SD & $51 \pm 14.2$ & $45.9 \pm 12.6$ & \\
\hline Median & 50 & 43.9 & \\
\hline \multicolumn{4}{|l|}{ RCS total } \\
\hline Little concerned & $1(3.1 \%)$ & $4(12.5 \%)$ & \multirow{3}{*}{0.314} \\
\hline Somewhat concerned & $26(81.3 \%)$ & $25(78.1 \%)$ & \\
\hline Very concerned & $5(15.6 \%)$ & $3(9.4 \%)$ & \\
\hline
\end{tabular}

- Mann Whitney test for non-parametric quantitative data between the two groups

- $\quad$ Significant level at P value $<0.05$ 
Impact of Tailored Educational Program of Quality of Life Improvement on Women Undergoing Breast Cancer Treatment at El-Minia Region, Egypt

Table4. Distribution of the studied women in the study group according to sexual function at first and last visit.

\begin{tabular}{|c|c|c|c|c|c|c|}
\hline \multirow{2}{*}{$\begin{array}{c}\text { Female Sexual Function } \\
\text { index (FSFI) }\end{array}$} & \multicolumn{3}{|c|}{ pre } & \multicolumn{3}{|c|}{ Post } \\
\hline & Study & Control & P-value & Study & Control & P-value \\
\hline $\begin{array}{c}\text { Female sexual } \\
\text { dysfunction FSD }^{(\$)}\end{array}$ & & & \multirow{3}{*}{1} & & & \multirow{3}{*}{$0.043^{*}$} \\
\hline Not present & $2(6.25 \%)$ & $2(6.25 \%)$ & & $9(28.12 \%)$ & $2(6.25 \%)$ & \\
\hline Present & 30 (93.75\%) & $30(93.75 \%)$ & & $23(71.8 \%)$ & $30(93.75 \%)$ & \\
\hline
\end{tabular}

- $\quad$ Wilcoxon Signed rank test for non-parametric quantitative data within each group

- (\$) McNemar test for repeated measure qualitative data

- $\quad$ Significant level at P value $<0.05$

Table5. Distribution of the studied women in the study and control group according to cancer specific stress at first and last visit.

\begin{tabular}{|c|c|c|c|c|c|c|}
\hline \multirow{2}{*}{ Cancer-specific stress (CSS) } & \multicolumn{3}{|c|}{ pre } & \multicolumn{3}{|c|}{ Post } \\
\hline & Case & Control & $P$ value & Case & Control & $P$ value \\
\hline \multicolumn{7}{|l|}{ Cancer-specific stress ${ }^{(\$)}$} \\
\hline No & $2(6.3 \%)$ & $3(9.4 \%)$ & \multirow{4}{*}{0.819} & $13(40.6 \%)$ & $4(12.5 \%)$ & \multirow{4}{*}{$0.000^{* *}$} \\
\hline Mild & $3(9.4 \%)$ & $2(6.3 \%)$ & & $9(28.1 \%)$ & $6(18.8 \%)$ & \\
\hline Moderate & $0(0 \%)$ & $0(0 \%)$ & & $4(12.5 \%)$ & $0(0 \%)$ & \\
\hline Severe & 27 (84.4\%) & 27 (84.4\%) & & $6(18.8 \%)$ & $22(68.8 \%)$ & \\
\hline
\end{tabular}

- Wilcoxon Signed rank test for non-parametric quantitative data within each group

- \$)McNamara test for repeated measure qualitative data

- $\quad$ Significant level at $P$ value $<0.05$

Table6. Distribution of the studied women in the study and control group according to cancer QOL at first and last visit.

\begin{tabular}{|c|c|c|c|c|c|c|}
\hline \multirow[b]{2}{*}{ Quality of life } & \multicolumn{3}{|c|}{ pre } & \multicolumn{3}{|c|}{ Post } \\
\hline & Study & Control & $\begin{array}{c}P \\
\text { value }\end{array}$ & Study & Control & P value \\
\hline Poor & $5(15.5 \%)$ & 7 (21.8\%) & \multirow{3}{*}{0.607} & $0(0 \%)$ & $8(25 \%)$ & \multirow{3}{*}{$0.000^{* *}$} \\
\hline Moderate & $23(71.8 \%)$ & $23(71.8 \%)$ & & $11(34.37 \%)$ & $22(68.75 \%)$ & \\
\hline good & $4(12.5 \%)$ & $2(6.2 \%)$ & & $21(65.62 \%)$ & $2(6.25 \%)$ & \\
\hline
\end{tabular}

- Wilcoxon Signed rank test for non-parametric quantitative data within each group

- Significant level at P value $<0.05$ 
Impact of Tailored Educational Program of Quality of Life Improvement on Women Undergoing Breast Cancer Treatment at El-Minia Region, Egypt

Table7. The relationship between the studied women QOL (dependent), socio-demographic data, social stressors, and clinical characteristics (independents).

\begin{tabular}{|c|c|c|c|c|c|c|c|c|}
\hline \multirow{3}{*}{ Item } & \multicolumn{4}{|c|}{ Pre } & \multicolumn{4}{|c|}{ post } \\
\hline & \multicolumn{2}{|c|}{ Study group } & \multicolumn{2}{|c|}{ Control group } & \multicolumn{2}{|c|}{ Study group } & \multicolumn{2}{|c|}{ Control group } \\
\hline & $\mathbf{r}$ & $\begin{array}{c}\mathrm{P} \\
\text { value }\end{array}$ & $\mathbf{r}$ & $P$ value & $\mathbf{r}$ & $\begin{array}{c}\mathrm{P} \\
\text { value }\end{array}$ & $\mathbf{r}$ & $\begin{array}{c}P \\
\text { value }\end{array}$ \\
\hline \multicolumn{9}{|l|}{ A- Socio-demographic data } \\
\hline Age & 0.197 & 0.280 & 0.133 & 0.467 & -0.021 & 0.911 & 0.166 & 0.364 \\
\hline Residence (Rural) & -0.082 & 0.656 & -0.267 & 0.139 & 0.044 & 0.809 & -0.128 & 0.484 \\
\hline Education & -0.276 & 0.126 & 0.228 & 0.210 & -0.224 & 0.218 & -0.077 & 0.674 \\
\hline Education of husband & -0.098 & 0.593 & 0.490 & $0.004 *$ & -0.223 & 0.221 & 0.104 & 0.570 \\
\hline Occupation & 0.070 & 0.704 & --- & --- & -0.065 & 0.723 & ---- & --- \\
\hline Occupation of husband & -0.120 & 0.511 & 0.315 & 0.079 & -0.286 & 0.112 & 0.126 & 0.492 \\
\hline Income & -0.049 & 0.790 & 0.595 & $<0.001 *$ & -0.185 & 0.312 & 0.275 & 0.128 \\
\hline Age at menarche & -0.346 & 0.052 & 0.052 & 0.778 & -0.003 & 0.987 & -0.036 & 0.845 \\
\hline Age at marriage & -0.071 & 0.700 & 0.008 & 0.964 & -0.414 & $0.018^{*}$ & -0.165 & 0.366 \\
\hline Period of marriage & 0.059 & 0.748 & 0.149 & 0.415 & 0.105 & 0.568 & 0.177 & 0.333 \\
\hline Age at first child birth & 0.077 & 0.677 & 0.047 & 0.800 & -0.104 & 0.569 & -0.139 & 0.457 \\
\hline Age at last child birth & 0.029 & 0.875 & 0.013 & 0.946 & -0.253 & 0.162 & -0.145 & 0.438 \\
\hline Menopause & 0.380 & $0.032 *$ & -0.046 & 0.802 & -0.102 & 0.578 & -0.081 & 0.660 \\
\hline \multicolumn{9}{|l|}{ B- Social stressors } \\
\hline Children Lower than 15 years & 0.168 & 0.358 & 0.281 & 0.119 & 0.070 & 0.704 & -0.139 & 0.449 \\
\hline Financial stressors & 0.203 & 0.264 & -0.082 & 0.655 & -0.227 & 0.212 & -0.082 & 0.655 \\
\hline Emotional ill & 0.238 & 0.190 & -0.357 & $0.045^{*}$ & 0.014 & 0.939 & 0.021 & 0.909 \\
\hline Chronic event & 0.145 & 0.430 & -0.115 & 0.532 & 0.042 & 0.820 & 0.115 & 0.532 \\
\hline Problems related to drug & 0.243 & 0.180 & -0.091 & 0.620 & -0.195 & 0.284 & 0.213 & 0.243 \\
\hline \multicolumn{9}{|l|}{ C- Clinical characteristics } \\
\hline Stage at diagnosis & -0.421 & 0.134 & -0.029 & 0.932 & -0.246 & 0.397 & 0.082 & 0.810 \\
\hline Surgical treatment & 0.120 & 0.511 & -0.198 & 0.278 & 0.418 & $0.017^{*}$ & 0.058 & 0.752 \\
\hline Chemotherapy & -0.028 & 0.879 & ---- & ---- & 0.364 & $0.041 *$ & ---- & ---- \\
\hline Radiotherapy & 0.105 & 0.568 & 0.075 & 0.684 & 0.161 & 0.379 & -0.021 & 0.907 \\
\hline Hormonal therapy & 0.052 & 0.776 & 0.049 & 0.791 & -0.227 & 0.212 & 0.088 & 0.634 \\
\hline
\end{tabular}

- Non-parametric Spearman's rho correlation

- $\quad$ *:Significant Level at P value $<0.05$ 
Impact of Tailored Educational Program of Quality of Life Improvement on Women Undergoing Breast Cancer Treatment at El-Minia Region, Egypt

Table8. The relationship between QOL (outcome) of the study and control group and their reproductive concerns, sexual function, and cancer specific stress (predictors.

\begin{tabular}{|c|c|c|c|c|c|c|c|c|c|c|c|c|c|c|c|}
\hline \multirow{4}{*}{\begin{tabular}{|l} 
quality \\
of life \\
(outtome)
\end{tabular}} & \multicolumn{8}{|c|}{ Pre } & \multicolumn{7}{|c|}{ Post } \\
\hline & \multicolumn{4}{|c|}{ Study group } & \multicolumn{4}{|c|}{ Control group } & \multicolumn{3}{|c|}{ Study group } & \multicolumn{4}{|c|}{ Control group } \\
\hline & \multicolumn{3}{|c|}{ QOL } & \multirow[b]{2}{*}{$\begin{array}{c}P \\
\text { value }\end{array}$} & \multicolumn{3}{|c|}{ QOL } & \multirow[b]{2}{*}{ P value } & QOL & & \multirow{2}{*}{$\begin{array}{c}\mathrm{P} \\
\text { value }\end{array}$} & \multirow[b]{2}{*}{$\begin{array}{l}\text { Poor } \\
\text { N = } 8\end{array}$} & \multirow[b]{2}{*}{$\begin{array}{c}\text { Moderate } \\
\mathrm{N}=22\end{array}$} & \multirow[b]{2}{*}{$\begin{array}{l}\text { Good } \\
\mathrm{N}=2\end{array}$} & \multirow{2}{*}{$\begin{array}{c}P \\
\text { value }\end{array}$} \\
\hline & $\begin{array}{l}\text { Poor } \\
\mathrm{N}=5\end{array}$ & $\begin{array}{c}\text { Moderate } \\
\mathrm{N}=23\end{array}$ & $\begin{array}{l}\text { Good } \\
\mathrm{N}=4\end{array}$ & & $\begin{array}{l}\text { Poor } \\
\mathrm{N}=7\end{array}$ & $\begin{array}{c}\text { Moderate } \\
\mathrm{N}=\mathbf{2 3}\end{array}$ & $\begin{array}{l}\text { Good } \\
\mathrm{N}=2\end{array}$ & & $\begin{array}{c}\text { Moderate } \\
\mathrm{N}=11\end{array}$ & $\begin{array}{l}\text { Good } \\
\mathrm{N}=21\end{array}$ & & & & & \\
\hline \multicolumn{16}{|l|}{ RCA } \\
\hline \begin{tabular}{|l} 
Little \\
Concerned
\end{tabular} & $\begin{array}{c}1 \\
(20 \%)\end{array}$ & $0(0 \%)$ & $0(0 \%)$ & & $0(0 \%)$ & $4(16.1 \%)$ & $0(0 \%)$ & & & & & & & & \\
\hline $\begin{array}{l}\text { Somewhat } \\
\text { concerned }\end{array}$ & $\begin{array}{c}4 \\
(80 \%)\end{array}$ & $\begin{array}{c}18 \\
(78.26 \%)\end{array}$ & $\begin{array}{c}4 \\
(100 \%)\end{array}$ & 0.109 & $\begin{array}{c}6 \\
(85.7 \%)\end{array}$ & $\begin{array}{c}17 \\
(74.2 \%)\end{array}$ & $\mid \begin{array}{c}2 \\
(87.5 \%)\end{array}$ & 0.704 & & & & & & & \\
\hline $\begin{array}{l}\text { Very } \\
\text { concerned }\end{array}$ & $0(0 \%)$ & $\begin{array}{c}5 \\
(21.73 \%)\end{array}$ & $0(0 \%)$ & & $\begin{array}{c}1 \\
(14.3 \%)\end{array}$ & $2(9.7 \%)$ & $\left.\begin{array}{c}0 \\
(12.5 \%)\end{array}\right)$ & & & & & & & & \\
\hline \multicolumn{16}{|l|}{ FSI } \\
\hline $\begin{array}{l}\text { Without } \\
\text { FSD }\end{array}$ & $0(0 \%)$ & $1(4.34 \%)$ & $\begin{array}{c}1 \\
(25 \%)\end{array}$ & \multirow{2}{*}{0.237} & $0(0 \%)$ & $1(4.34 \%)$ & $1(50 \%)$ & \multirow{2}{*}{$0.028^{*}$} & $2(18.2 \%)$ & $0(0 \%)$ & & $0(0 \%)$ & $2(9.1 \%)$ & $0(0 \%)$ & \multirow[b]{2}{*}{ ) } \\
\hline With FSD & $\begin{array}{c}5 \\
(100 \%)\end{array}$ & $\begin{array}{c}22 \\
(95.65 \%)\end{array}$ & $\begin{array}{c}3 \\
(75 \%)\end{array}$ & & $\begin{array}{c}7 \\
(100 \%)\end{array}$ & $\begin{array}{c}22 \\
(95.6 \%)\end{array}$ & $1(50 \%)$ & & $9(81.8 \%)$ & $\begin{array}{c}21 \\
(100 \%)\end{array}$ & & \begin{tabular}{|c|}
8 \\
$(100 \%)$
\end{tabular} & $20(90.9 \%)$ & $\begin{array}{c}2 \\
(100 \%)\end{array}$ & \\
\hline \multicolumn{16}{|l|}{ CSS } \\
\hline NO & $0(0 \%)$ & $1(4.34 \%)$ & $\begin{array}{c}1 \\
(25 \%)\end{array}$ & \multirow{4}{*}{$0.012 *$} & $0(0 \%)$ & $3(13 \%)$ & $0(0 \%)$ & \multirow{4}{*}{0.079} & $0(0 \%)$ & $\left|\begin{array}{l}13 \\
(33.3 \%)\end{array}\right|$ & \multirow{4}{*}{$0.001 *$} & $0(0 \%)$ & $4(18.2 \%)$ & $0(0 \%)$ & \multirow{4}{*}{0.193} \\
\hline Mild & $0(0 \%)$ & $1(4.34 \%)$ & $\begin{array}{c}2 \\
(50 \%)\end{array}$ & & $0(0 \%)$ & $1(4.34 \%)$ & $1(50 \%)$ & & $3(27.2 \%)$ & $\begin{array}{l}6 \\
(66.7 \%)\end{array}$ & & $0(0 \%)$ & $5(22.7 \%)$ & $1(50 \%)$ & \\
\hline Moderate & $0(0 \%)$ & $0(0 \%)$ & $0(0 \%)$ & & $0(0 \%)$ & $0(0 \%)$ & $0(0 \%)$ & & $4(36.36 \%)$ & $0(2.8 \%)$ & & $0(0 \%)$ & $0(0 \%)$ & $0(0 \%)$ & \\
\hline Severe & $\begin{array}{c}5 \\
(100 \%)\end{array}$ & $\begin{array}{c}21 \\
(91.3 \%)\end{array}$ & $\begin{array}{c}1 \\
(25 \%)\end{array}$ & & $\begin{array}{c}7 \\
(100 \%)\end{array}$ & $\begin{array}{c}19 \\
(82.6 \%)\end{array}$ & $1(50 \%)$ & & $4(36.36 \%)$ & $\begin{array}{l}2 \\
(13.9 \%)\end{array}$ & & $\begin{array}{c}8 \\
(100 \%)\end{array}$ & $13(59.1 \%)$ & $1(50 \%)$ & \\
\hline
\end{tabular}

- Pearson's correlation

- $\quad$ *:Significant Level at P value $<0.05$

\section{Discussion}

Breast malignant neoplastic disease \& hormone receptor positive (HR+) breast cancer incidence vary across the world with higher incidence in developed nations. Annually, breast cancer is the most common malignancy among women in most developed \& developing areas of the globe with almost a million new lawsuits. ${ }^{[30,31]}$

The therapeutic approach of patients with breast and gynecological cancer involves a high degree of concern regarding their survival. ${ }^{[32]}$ The diagnosis of cancer generally has a devastating effect on the life of the recipient. Fear of the mutilations and disfigurations that can result from the treatment, as well as the fear of death and the many losses in the emotional, social and material spheres almost always occur. In this way, cancer is still a difficult secret to be shared, narrated and heard, even for women who are culturally more encouraged to share, integrate and socialize experiences, which probably compromises their QOL. ${ }^{[33]}$ 
Impact of Tailored Educational Program of Quality of Life Improvement on Women Undergoing Breast Cancer Treatment at El-Minia Region, Egypt

The technological development of oncology has resulted in new treatments with great healing potential. However, while survival has increased, benefits related to QOL have not been achieved. ${ }^{[34]}$ Quality of life (QOL) issues are of interest in oncology because effective modern methods of treatment and detection have led to an increase in the number of long-term survivors. ${ }^{[35]}$

According to the studied women socio-demographic characteristics, the result of present study showed that no statistical significant difference between the two groups which denote homogeneity of the groups. The mean age of the subjects in the study group was $39.5 \pm 6.2$ as compared with $41.2 \pm 7.3$ in the control group. Near to half of subjects $(46.9 \% \& 43.8 \%$ ), respectively, in both groups were illiterate, the majority of the subjects (84.4\% \% 90.6\%), respectively, in both groups were housewives. More than half (56.3\%) of the subject in study and $65.6 \%$ in the control groups live in rural areas. More than half of the subject of the study group (56.3\%) reported enough income and (65.6\%) of the control group reported in sufficient income. These findings are consistent with Hamzehgardeshi et al., (2017) ${ }^{[36]}$ in Iran who studied effect of midwifery-based counseling support program on body image of breast cancer women survivors and reported that there was no significant difference between the two groups in terms of age, stage of treatment, education, length of the married life, occupation, number of chemotherapies, and number of children. The mean age of the intervention group was $46.77 \pm 6.85$ and that of the control group was $48.92 \pm 5.86$, but our patients were different in age. This is in line with well-known international age trends whereby the average age of subjects in developing countries is less than that in the developed countries.

Regarding to reproductive concerns, the majority (81.3\% \& 78.1\%), respectively, of the case in the study and control group were somewhat concerned, for instance, some survivors may view their childbearing plans as completed, or/and due to the fact that patients usually face with unhealthy feelings and due to failure to comply with major life issues, they focus on management of disease and related treatment side effects that affect their satisfaction of their role within the family as evidenced by personal health (it was significant predictor affecting reproductive concerns of the study group), also they may ignore to talk with their physician about the impact of cancer therapy on their fertility before starting treatment. These findings aren't consistent with Ruddy et al., $2014{ }^{[37]}$ in Aurora who studied fertility concerns and preservation strategies in young women with breast cancer, and found that 301 women, or almost half, reported no concern about fertility, 83 (13\%) were a little concerned, 88 (14\%) were somewhat concerned, and 148 (24\%) were very concerned.

In relation to sexual function, there was a statistical significant difference in relation to impact of the health education program on sexual function; there was a statistical significant difference in relation to impact of the health education program on sexual function, as there was a significant change in the sexual function index. The percentage of women with sexual dysfunction in the study and control group was $(71.8 \%$ \& 93.75\%), respectively, and the percentage of women who were healthy (have no sexual dysfunction was $(28.12 \%$ \& $6.25 \%)$, respectively, in the two groups ( $\mathrm{P}=0.043)$.

According to the Egyptian family culture, marital relationship is a highly personal and private matter and it should be noted that sexual orientation is one of the least important aspects of life that isn't strongly related to women quality of life. It is also not a factors affecting interpersonal communication, in the present study and through attendance in the sessions and telephone contact attempted to answer patients' questions with empathic listening and the atmosphere for supporting and providing information to enable their problem solving, their self-care and their increased abilities to cope with the problems Several findings were consistent in study by Anderson et al., $2015^{[38]}$ in Australia who studied facilitating lifestyle changes to manage menopausal symptoms in women with breast cancer: a randomized controlled pilot trial of the pink women's wellness program, who found improvements in sexual function were observed in the intervention group compared to controls, but effect sizes were generally modest and of unclear clinical significance. 
Impact of Tailored Educational Program of Quality of Life Improvement on Women Undergoing Breast Cancer Treatment at El-Minia Region, Egypt

There was clear effect of the health education program on traumatic stress reactions to cancer diagnosis $\&$ treatment, as in the last visit there was clear effect of the health education program on traumatic stress reactions to cancer diagnosis and treatment. As (18.8\%) of the study group, as compared with (68.8\%) of the control group had severe traumatic stress disorder, and (40.6\%) of the women in the study group vs. (12.5\%) of the control group were healthy with no stress. ( $\mathrm{P} \leq 0.001)$.

In order to enhance psychological adjustment to cancer and its treatment this group of patients learned to use avoidant behavior, warding off repeated thoughts about the stressful event as having cancer and receiving treatment to decrease a stress reaction. Also teaching them to manage their physical \& mental health problems concurrently with meeting with family members and informing them about management strategies and facilitating communication between patients \& medical providers were also vital components. These findings are in line with Loh et al (2013) in Malaysia who studied effectiveness of a patient self-management programme for breast cancer as a chronic illness and stated that the differential positive impact on depression, anxiety, and stress. ${ }^{[39]}$ Also with findings from a study by Brewin et al. (1998) in London who studied memory processes and the course of anxiety \& depression in cancer patients, where the importance of IES intrusion as a predictor for prolonged adverse psychological reactions in cancer patients indicated the importance of interventions in order to facilitate psychological adjustment. ${ }^{[40]}$

Previous studies displayed improving in women's perception and knowledge after implementing an educational program. ${ }^{[41]}$ The research results showed that QOL of the patients with breast cancer has been enhanced under the influence of health education program. As $(65.62 \%)$ of the study group as compared with $(6.25 \%)$ of the control group had good QOL and no one $(0.0 \%)$ of the study group vs. (25.0\%) of the control group had poor QOL with statistically significant difference $(\mathrm{p}<0.001)$. Thus, it can be said that health education program enhances physical, social, emotional, functional wellbeing and additional concerns related to breast cancer, and on enabling women to proactively live with a cancer condition.

These findings were concurrent with study reported by Klafke et al (2015) in Germany who evaluate the effectiveness of an intervention involving CAM therapies and counseling on CAM as complementing the supportive care of breast and gynecologic cancer patients undergoing chemotherapy. ${ }^{[42]}$ It is hypothesized that this intervention increases HRQOL and clustered symptoms over the chemotherapy regimen and follow-up in this outpatient population. Also with findings of Shahsavari et al., (2015) ${ }^{[43]}$ who studied effect of self-care education on the QOL in patients with breast cancer and showed that QOL of the patients with breast cancer has been enhanced under the influence of self-care education, and with Loh et al (2013) [39] in Malaysia who studied effectiveness of a patient self-management programme for breast cancer as a chronic illness and stated that all dimensions of QOL increased significantly in the intervention group after performing a 1-month selfmanagement program compared with the control one. Moreover these findings aren't in line with Speck et al., 2010 in Philadelphia USA who studied changes in the body image \& relationship scale following a one-year strength training trial for breast cancer survivors with or at risk for lymphedema, and found an improvement in body image perception after rehabilitative intervention (twice a week for 13 weeks), but they did not find any improvement in QOL. ${ }^{[44]}$

Regarding the relationship between the studied women quality of life, socio-demographic data, social stressors, and clinical characteristics there is no significant correlation between socio-demographic data and QOL as regards study \& control groups in the first visit except on the study group, there was significant positive correlation with menopausal status and quality of life, in the control group; there was a significant positive correlation between education of husband, income and quality of life, and significant negative correlation with presence of emotional illness and quality of life. Regarding the clinical characteristics, in the control group there 
Impact of Tailored Educational Program of Quality of Life Improvement on Women Undergoing Breast Cancer Treatment at El-Minia Region, Egypt

was a significant negative correlation between stage at diagnosis and quality of life. In the last visit there is no significant correlation between socio-demographic data and QOL as regards study and control groups except on the study group, there was significant negative correlation with age at marriage and QOL and significant positive correlation with receiving surgical and chemotherapy and quality of life.

The fact that the intervention group improved more implies that intervention worked so well in improving QOL as they engaged and followed the women over time teaching them to manage their physical and mental health problems concurrently. These findings are in line with Wilailak et al. (2011) in Thailand regarding association with financial status who studied QOL in gynecologic cancer survivors compared to healthy check-up women and found the QOL scores were higher in gynecologic cancer patients after treatment. The factors that associated with the higher score in the patient group are having husband as a caregiver, no financial problem, Eastern Cooperative Oncology Group score 0 or 1 and having high school or higher education. ${ }^{[45]}$ Moreover, it contradict with Awadalla et al. (2007) in Kuwait who studied factors associated with QOL of outpatients with breast cancer \& gynecologic cancers and their family caregivers: a controlled study and found that education was the only caregiver characteristic that had a significant association with patient's QOL. ${ }^{[46]}$ Additionally, Loizzo et al. (2010) confirmed that patients who were married, with higher education, better employment, and with longer duration of illness had higher QOL. ${ }^{[47]}$ Patients on radiotherapy and their caregivers had higher QOL scores. Also Greimel et al., 2002 in Austria who studied prospective assessment of QOL of female cancer patients, and reported that the site of disease had marginal impact on QOL during active treatment and no impact after completion of treatment. ${ }^{[48]}$

Regarding to relationship of predictor and outcomes, there is no significant difference between reproductive concerns and QOL in the study and control group in the first and last visit $(\mathrm{P}>0.05)$. Also in the first visit there was statistically significant difference between female sexual function and QOL in the study group as (100.0\%) of cases who had poor QOL had sexual dysfunction ( $>$ > 0.05). There was statistically significant difference between cancer specific stress and QOL as (100.0\%) of the study group who had Poor QOL had severe stress in the first visit $(P>0.05)$, while in the last visit (66.7\%) of women who had good QOL had mild stress $(P>0.05)$.

\section{CONCLUSION}

The health education program showed evidence of improved QOL with a reduction in the sexual dysfunction, and lower stress levels. As a study to investigate health education following a cancer diagnosis in Egypt, its contribution is threefold. Firstly, it adds voice to support the education interventions for breast cancer as an emerging chronic illness. Secondly, it has added to the sparse literature concerning the needs of the Egyptian women with breast cancer. However, generalization to the wider settings must be done. Thirdly, if health education is added to the routine cares provided to these patients by nurses, it can influence treatment results and highlight the importance of nurses' roles. Thus, it can be said that health education program enhances physical, social, emotional, functional wellbeing and additional concerns related to breast cancer, and on enabling women to proactively live with a cancer condition.

\section{RECOMMENDATIONS}

Based upon findings of the current study,

1. It is suggested to heighten awareness and knowledge about the treatment-related side effects among the nursing staff in the department for the nursing-care of this group of patients.

2. More studies are needed to investigate longer-term effect of such programs and plan individualized education program emphasizing on unique needs of each patient. 
Impact of Tailored Educational Program of Quality of Life Improvement on Women Undergoing Breast Cancer Treatment at El-Minia Region, Egypt

\section{REFERENCES}

1. American Society of Clinical Oncology (ASCO). Breast Cancer: Statistics, Approved by the Cancer.Net Editorial Board, 04/2017.

2. Qalawa, Sh., Eldeeb, A., \& Hassan, H. Young Adult Women's intention regarding breast and cervical cancer screening in Beni-Suef. Scientific Research Journal, 2015; 3(3): 11-24.

3. Centers for Disease Control and Prevention 1600, Clifton Rd. Atlanta, May 29, 2013.

4. Ibrahim M. Khaled M., Baraka H., Kamal H. Cancer Incidence in Egypt: Result of the National Population-Based Cancer Registery Program. Journal of Cancer Epidemiology, 2014; Arabic ID 437971, 18 pages.

5. National Cancer Institute (NCI) Dictionary. Gynecological cancer. 2010. Retrieved from http://www.caner. gov/dirctioary/?CdrID=54982.

6. Milne M., Wallman E., Gordon S., Courneya S. Effects of a combined aerobic and resistance exercise program in breast cancer survivors: A randomized controlled trial. Breast Cancer Res Treat, 2008; 108: 279 -88.

7. Cheema S., Gaul A. Full-body exercise training improves fitness and quality of life in survivors of breast cancer. J Strength Cond Res, 2006; 20: 14-21.

8. Dow KH. St Louis: Mosby Elsevier. Nursing Care of Women with Cancer. 2006.

9. Smeltzer C., Bare G., Hinkle L., Cheere H., Kluwer W. Brunner and Sudarth's Textbook of Medical-surgical Nursing, 2010; 12t $\mathrm{t}^{\mathrm{h}}$ ed. Philadelphia: Lippincot Williams and Wilkins: 1460-1700.

10. Schipper H. Guidelines and caveats for quality of life measurement in clinical practice and research. Oncology, 1990; 4(5): 51-57.

11. Cella F., Tulsky S., Gray G. et al. The Functional Assessment of Cancer Therapy (FACT) scale: development and validation of the general measure .Journal of Clinical Oncology, 1993;11: 570-579.

12. Gotay C., Moore D. Assessing quality of life in head and neck cancer. Quality of Life Research, 1992; 1: 5-17.

13. Wengström Y. Are women with breast cancer receiving sufficient education and information about their treatment? Nat Clin Pract Oncol,2008; 5 :62-3.

14. World Health Organization - Cancer Country Profiles, Egypt. 2014.

15. American Cancer Society. Cancer Facts and Figures, 2013. Atlanta, GA: American Cancer Society. 2013.

16. Miaskowski C., Dodd M., West C., Schumacher S., Tripathy D., et al. Randomized clinical trial of the effectiveness of a self-care intervention to improve cancer pain management. Journal of Clinical Oncology, 2004; 22: 1713-1720.

17. Gift A., Stommel M., Jablonski A., Given C. A cluster of symptoms over time in patients with lung cancer. Nursing Research, 2003; 52: 393-400.

18. Wenzel L., dealba I., Habbal R., Kluhsman C., Fairclough D., Krebs U., Aziz N. Quality of life in long-term cervical cancer survivors. Gynecologic Oncology, 2005; 97(2): 310-317.

19. Rosen R., Brown C., Heiman J., Leiblum S., Meston C., Shabsigh R., D’Agostino R. The Female Sexual Function Index (FSFI): a multidimensional self-report instrument for the assessment of female sexual function. Journal of Sexual and Marital Therapy, 2000; 26(2): 191-208. 
Impact of Tailored Educational Program of Quality of Life Improvement on Women Undergoing Breast Cancer Treatment at El-Minia Region, Egypt

20. Marmar R., Weiss S., Metzler J., Ronfeldt M., Foreman C. Stress responses of emergency services personnel to the Loma Prieta earthquake Interstate 880 freeway collapse and control traumatic incidents. Journal of Traumatic Stress, 1996; 9(1): 63-85.

21. Shapinsky C., Rapport J., Henderson J., Axelrod N. Civilian PTSD scales: relationships with trait characteristics and everyday distress. Assessment, 2005; 12(2): 220-230.

22. Asukai N., Kato H. et al. Reliability and validity of the Japanese-language version of the Impact of event scale-revised (IES-R-J). Journal of Nervous and Mental Disease, 2002; 190 (3): 175-182.

23. Creamer M. Bell R. Falilla S. Psychometric properties of the Impact of Event Scale-Revised. Behaviour Research and Therapy, 2002; 41: 1489-1496.

24. Kawamura N. Yoshiharu K., Nozomu A. Suppression of Cellular Immunity in Men with a Past History of PostTraumatic Stress Disorder. American Journal of Psychiatry, 2001; 158: 484-486

25. Wan C., Zhang D., Yang Z., Tu X., Tang W., Feng C., Wang H., Tang X. Validation of the simplified Chinese version of the FACT-B for measuring quality of life for patients with breast cancer. Breast Cancer Res Treat, 2007; 106: 413-418.

26. Brady M., Cella DF., Mo F., Bonomi AE., Tulsky DS., Lloyd SR., Deasy S., Cobleigh M., Shiomoto G. Reliability and validity of the functional assessment of cancer therapy - breast quality-of-life instrument. J Clin Oncol, 1997; 15: 974-986.

27. Ng R., Lee CF., Wong NS., Luo N., Yap YS., Lo SK., Chia WK., Yee A., Krishna L., Goh C., Cheung YB. Measurement properties of the English and Chinese versions of the Functional Assessment of Cancer Therapy-Breast (FACT-B) in Asian breast cancer patients. Breast Cancer Res Treat, 2012; 131: 619-625

28. Padilla V., Ferrell B., Grant M., Rhiner M. Defining the content domain of quality of life for cancer patients with pain. Cancer Nursing, 1990; 13(2): 108-115.

29. Ersek M., Ferrell R., Dow H., Melancon H. Quality of life in women with ovarian cancer. Western Journal of Nursing Research, 1997; 9(3): 334-350.

30. Hassan H., Bayoumi M., \& Atwa A. Emotional Distress Associated with Gynecologic and Breast Cancer in Beni-Suef City. International Journal of Science and Research, 2016; 5(2): 1118-1129.

31. Dey S. Urban-Rural Differences of Female Cancers in Gharbiah, Egypt. A thesis submitted to School of Public Health, Michigan University, 2009.

32. Regino A., Elias T., Silveira1 C., Pereira G., Pissetti C., Silva S. Quality of Life of Patients with Breast and Gynecological Cancer Faced with Anticancer Chemotherapy, 2017; 10(233) doi: 10.3823/2503.

33. Silva C. Câncer de mama e sofrimento psicológico: aspectos relacionados ao feminino. Psicol Estud, 2008; 13(2): 231-7. Available from: http://www.scielo.br/pdf/pe/v13n2/a05v13n2

34. Lugo J., Nápoles M., Pérez I., Ordaz N., Luzardo M., Fernández L. Development and evaluation of an instrument to measure health-related quality of life in Cuban breast cancer patients receiving radiotherapy. MEDICC Rev, 2014; 16(3-4): 35-41. Available from: http://www.medicc.org/mediccreview/index.php

35. Penson T, Wenzel B., Vergote I., Cella D. Quality of life considerations in gynecologic cancer. Int J Gynaecol Obstet, 2006; 95: 247-257.

36. Hamzehgardeshi Z., Moosazadeh M., Elyasi E., Janbabai G., et al., Effect of Midwifery-Based Counseling Support Program on Body Image of Breast Cancer Women Survivors, Asian Pac J Cancer Prev; 2017; 18(5): 1293-1299. 
Impact of Tailored Educational Program of Quality of Life Improvement on Women Undergoing Breast Cancer Treatment at El-Minia Region, Egypt

37. Ruddy J., et al. Prospective Study of Fertility Concerns and Preservation Strategies in Young Women with Breast Cancer, Journal of Clinical Oncology, 2014, http://jco.ascopubs.org/content/32/11/1151.

38. Anderson J., Seib C., Mccarthy L., Yates P., Porter-Steele J., Mcguire A., et al. Facilitating lifestyle changes to manage menopausal symptoms in women with breast cancer: a randomized controlled pilot trial of The Pink Women's Wellness Program. Menopause. 2015.

39. Loh SY., Packer T., Chinna K., Quek KF. Effectiveness of a patient self-management programme for breast cancer as a chronic illness: a non-randomised controlled clinical trial. J Cancer Surviv, 2013; 7(3): 331-42. Doi: 10.1007/s11764-013-0274-x. Epub 2013 Mar 22.

40. Brewin C., Watson M., Mccarthy S., Hyman P., Dayson D. Memory processes and the course of anxiety and depressionin cancer patients. Psychol Med, 1998; 28: 219 - 24.

41. Hassan H. Effectiveness of a structured teaching program on anxiety and perception regarding toxoplasmosis among seropositive pregnant women in Northern Upper Egypt. Clinical Nursing Studies. 2018; 6(1): 1-19. https://doi. 10.5430/cns.v6n1p1.

42. Klafke N., Mahler C., Hagens C., et al. A complex nursing intervention of complementary and alternative medicine (CAM) to increase quality of life in patients with breast and gynecologic cancer undergoing chemotherapy: study protocol for a partially randomized patient preference trial, 2015; 16: 51.

43. Shahsavari, H., Matory, P., 1 Zare,Z., Taleghani,F., and Mohammad Akbari Kaji3 J Educ Health Promot. 2015; 4: 70. Effect of self-care education on the quality of life in patients with breast cancer

44. Speck C., Gross R., Hormes J. et al. Changes in the body image and relationship scale following a one-year strength training trial for breast cancer survivors with or at risk for lymphedema, Breast Cancer Research and Treatment, 2010; 121(2): 421-430.

45. WilailakS., LertkhachonsukA., Lohacharoenvanich N., Luengsukcharoen S., et al. Quality of life in gynecologic cancer survivors compared to healthy check-up women J Gynecol Oncol, 2011; 22(2): 103-109.

46. Awadalla W., Ohaeri U., Gholoum A., Khalid O., Hamad M., Jacob A. Factors associated with quality of life of outpatients with breast cancer and gynecologic cancers and their family caregivers: a controlled study. BMC Cancer, 2007;7:102.

47. Loizzo J., Peterson J., Charlson E., Wolf J., Margaret M., et al. the effect of a contemplative self-healing program on quality of life in women with breast and gynecologic cancers Alternative Therapies in Health and Medicine; Aliso Viejo.16.3, 2010;- (May/Jun): 30-7.

48. Thiel G., Peintinger F., Cegnar I., Pongratz E. Prospective assessment of quality of life of female cancer patients. Gynecol Oncol, 2002; 85: 140-147.

Citation: Fatma S. Nady, Mamdouh E. said, Entisar M. Youness, Hanan E. Hassan, "Impact of Tailored Educational Program of Quality of Life Improvement on Women Undergoing Breast Cancer Treatment at El-Minia Region, Egypt". American Research Journal of Gynaecology, 1(1): 1-17.

Copyright (c) Fatma S. Nady, Mamdouh E. said, Entisar M. Youness, Hanan E. Hassan, This is an open access article distributed under the Creative Commons Attribution License, which permits unrestricted use, distribution, and reproduction in any medium, provided the original work is properly cited. 